\section{Commentary: Tricuspid insufficiency after heart transplant: More of an art than a science}

\author{
J. Hunter Mehaffey, MD, MSc, \\ Robert B. Hawkins, MD, MSc, and John A. Kern, MD
}

In this issue of the Journal, Hajiyev and colleagues present a single-center retrospective analysis of tricuspid insufficiency (TR) after orthotropic heart transplant (OHT) using a biatrial technique performed between 1986 and $2010 .{ }^{1}$ This highly respected group from Berlin should be commended on their robust early experience with OHT and the scientific approach they take in attempting to identify factors associated with the development of "functional" TR. They identify the following risk factors as associated with post-OHT TR in multivariable analysis: (1) donor-torecipient right atrium anterior wall ratio, (2) number of endomyocardial biopsies, and (3) recipient dialysis. The donor-to-recipient right atrium anterior wall ratio is important when attempting to recreate the atrial geometry.

After reading this article, I remain unclear as to what to do with these data and how to apply the results using a biatrial approach. The authors suggest leaving a "generous cuff." but this is not the entire picture. On the recipient side, there is the atrial septum as well as the free wall. Leaving the free wall larger with a shorter septum is very different in terms of potential distortion of the atrial geometry than leaving both the free wall and the septum long. In addition, there is the donor atrium and the incision to open the donor atrium. Where should this incision be? It is naive to think that only the recipient atrium is important; both the

\footnotetext{
From the Division of Thoracic and Cardiovascular Surgery, University of Virginia, Charlottesville, Va.

Disclosures: The authors reported no conflicts of interest.

The Journal policy requires editors and reviewers to disclose conflicts of interest and to decline handling or reviewing manuscripts for which they may have a conflict of interest. The editors and reviewers of this article have no conflicts of interest.

Received for publication Aug 21, 2020; revisions received Aug 21, 2020; accepted for publication Aug 25, 2020; available ahead of print Sept 21, 2020.

Address for reprints: J. Hunter Mehaffey, MD, MSc, Department of Thoracic and Cardiovascular Surgery, University of Virginia, PO Box 800679, Charlottesville, VA 22908-0709 (E-mail: jhm9t@ virginia.edu).

JTCVS Open 2020;4:35

2666-2736

Copyright (C) 2020 The Authors. Published by Elsevier Inc. on behalf of The American Association for Thoracic Surgery. This is an open access article under the CC BY-NCND license (http://creativecommons.org/licenses/by-nc-nd/4.0/).

https://doi.org/10.1016/j.xjon.2020.08.012
}

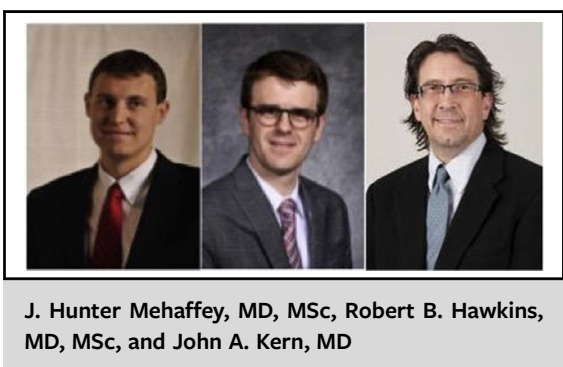

CENTRAL MESSAGE

There are technical factors associated with tricuspid insufficiency after biatrial heart transplant and a bicaval approach may simplify restoration of atrial geometry.

location and the length of the donor atrium will affect rotation of the right heart.

Several groups have described the importance of restoring atrial geometry during biatrial OHT. ${ }^{2,3}$ Simplification of atrial geometry is one of several reasons that several groups have moved to a bicaval approach, including these authors by their own report. With the use of a bicaval approach, many patients are also able to avoid a permanent pacemaker, and United Network for Organ Sharing database studies have demonstrated a slight survival advantage. ${ }^{4}$ Ultimately, the authors emphasize technical aspects of biatrial OHT that highlight how reconstruction of the atrial geometry is more of an art than a science. The heterogeneous nature of this reconstruction requires that the surgeon understand and be able to recreate native geometry.

\section{References}

1. Hajiyev V, Dandel M, Yeter R, Schoenrath F, Henning F, Falk V, et al. Functional tricuspid valve insufficiency after cardiac transplantation: which factor is the most important? J Thorac Cardiovasc Surg Open. 2020;4:25-32.

2. Traversi E, Pozzoli M, Grande A, Forni G, Assandri J, Viganò M, et al. The bicaval anastomosis technique for orthotopic heart transplantation yields better atrial function than the standard technique: an echocardiographic automatic boundary detection study. J Heart Lung Transplant. 1998;17:1065-74.

3. Dandel M, Hummel M, Loebe M, Weng Y, Müller J, Buz S, et al. Right atrial ge ometry and tricuspid regurgitation after orthotopic heart transplantation: benefits of a modified biatrial surgical technique. J Heart Lung Transplant. 2001;20:246-7.

4. Davies RR, Russo MJ, Morgan JA, Sorabella RA, Naka Y, Chen JM. Standard versus bicaval techniques for orthotopic heart transplantation: an analysis of the united network for organ sharing database. J Thorac Cardiovasc Surg. 2010; 140:700-8. 